\title{
Design Method for Radially Retractable Single DOF Plate Structure Based on Regular 1-Uniform Regular Tessellations
}

\author{
Düzenli Düzgün Tesselasyonlarla Tasarlanan Radyal Açılır Kapanır \\ Tek Serbestlik Dereceli Plak Strüktürler için Bir Tasarım Yöntemi
}

\author{
Aylin GAZi, Koray KORKMAZ
}

\section{ABSTRACT}

This paper is concerned with a method of designing single degree of freedom (DOF) radially retractable planar plate structures (RRPS). The shape of the plates are desired to be regular polygons and they are not allowed to overlap in any configuration and no gaps in the closed configuration. The method has been developed by translating geometric knowledge of tessellation in math. Therefore the paper firstly introduces the fundamentals of tessellations and then their classification based on polygon shape. After that it proposes a method of designing RRPS by using 1-uniform regular tessellations. The method identifies the plate types, shape and the way of connecting the plates with only revolute joints. Composed of various plates and joints, the proposed RRPSs based on 1- uniform regular tessellations are single DOF multi-loop planar mechanisms. Mobility analysis is made to prove the single DOF. After various mobility analysis, a theorem is developed to find the number of excessive plates. It is also introduced that there are passive joints besides excessive plates. When more plates and revolute joints are used in architectonic applications, the excessive plates and passive joints can be removed and reassembled if necessary for aesthetic or functional reasons. Finally, a single DOF radially retractable plate structure is proposed for a building façade as a sun shade to reduce the energy consumption.

Keywords: Dual; mechanism; mobility; retractable structure; tessellation.

\section{ÖZ}

Bu yazıda tek serbestlik dereceli (TSD), radyal açılır kapanır (RAK), düzlem plakalardan oluşan strüktürlerin tasarımı için bir yöntem geliştirilmiştir. Plakaların biçiminin düzgün çokgenler olması istenmektedir ve herhangi bir konfigürasyonda üst üste gelmemeleri ve strüktür kapandığında da hiçbir boşluk olmaması istenmektedir. Yöntem matematikteki tesselasyon geometri bilgisinden yararlanılarak geliştirilmiştir. Bu nedenle öncelikle tesselasyon, sonra poligon şekli dikkate alınarak yapılan bir sınıflandırma anlatılmıştır. Daha sonra düzenli tesselasyonlar kullanılarak RAK strüktür tasarımı yapmamızı sağlayacak yöntem açıklanmıştır. Yöntem plaka tiplerini ve şekillerini buldururken, sadece döner mafsallar ile plakaların nasıl monte edileceğinde de tasarımcıya yol gösterir. Bu yazıda düzenli poligonlardan oluşan tesselayonlardan yararlanılarak tasarlanan, çeşitli plakalar ve döner mafsallardan oluşan strüktürler TSD çok devreli mekanizmalardır. TSD mekanizmalar olduklarını kanıtlamak için birçok hareketlilik analizi yapılmıştır. Analizler sonucunda, çıkarıldığında mekanizmanın hareketliliğini etkilemeyen (fazla) plakaların olduğu ve bu fazla plakaların sayısını saptayabileceğimiz bir teori geliştirilmiştir. Ayrıca pasif döner mafsallar da olduğu saptanmıştır. Mimari uygulamalarda çok daha fazla sayıda plaka ve mafsal kullanıldığında, fazla plakalar ve pasif mafsallar estetik veya fonksiyonel sebeplerle gerektiğinde çıkarılıp tekrar monte edilebilir. Son olarak yapı enerji tüketimini azaltmak için bina dış cephesine RAK bir strüktür güneş kırıcı olarak önerilmiştir.

Anahtar sözcükler: Dual; mekanizma; mobilite; açılır kapanır strüktür; tesselasyon. 


\section{Introduction}

Over the last couple of decades, many concepts have been proposed for deployable structures employing bar or plates for use as a roof or a facade. Several deployable structures characterized by using scissor-like elements have been developed by Emilio Perez Pinero et al., ${ }^{[1]}$ Valcarcel, ${ }^{[2]}$ Escrig, ${ }^{[3]}$ Ziegler, ${ }^{[4]}$ Hernandez and Zalewski ${ }^{[5]}$ and Gantes. ${ }^{[6]}$ These deployable structures can be folded into a small volume but cannot attached to fixed supports which makes them unstable for long span. Hoberman discovered the angulated element consists of a pair of identical bars and applied to the retractable roofs. ${ }^{[7,8]}$ You and Pellegrino discovered multi-angulated element which consists of a bar with multiple kinks and with hinges at all kink points. ${ }^{[9]}$

Among the alternative approaches, flexible membrane or rigid plates are the covering materials. As a result of the durability problem of the membrane, many researchers focus on rigid plates for covering. Kassabian et al. investigated cover plates that can be attached to the multi- angulated bars. ${ }^{[10]}$ Jensen derived a method for finding simple rigid plates that can be attached to the deployable structure and which do not overlap during the expansion. An analytical solution for the shape of these rigid cover elements was derived by him. ${ }^{[11]}$ Later Jensen replaced the bars with flat plates which are connected with revolute joints at exactly the same locations as the original bar structure. ${ }^{[12]}$ With this approach, Jensen and Pellegrino led to the creation of a family of structures called radially retractable plate structures. Lou et al. used an analytical approach to derive a set of conditions that can be used to determine whether all of the pivot locations of a multi-angulated beam are enveloped by the boundary of its corresponding plate. Without any empirical or numerical analysis designers can choose an opening profile which suits their needs and then apply appropriate formula to determine the edges of the cover plates. $^{[13]}$ Buhl

et al. considered the shape of cover plates. They found suitable shapes of the plates by formulating an optimization problem. ${ }^{[14]}$ Besides these approaches which try to determine the shape of the cover plates, in 1998 Rodriguez and Chilton introduced swivel diaphragm which consists of polygonal plates. A hexagonal swivel diaphragm, consists of regular or irregular triangle plates and straight bars, could be linked together with revolute joints. However squares and pentagons presented problems of overlapping elements. ${ }^{[15]}$ In 1971, Chilton proposed the geometric transformation concept that is applicable to rigid expandable structures. ${ }^{[16]}$ His concept is divided into two types; the tessellation transformation concept a two-space expansion; and polyhedral transformation concept a three-space expansion. He identifies three basic types of transformations for regular polygons: face transformation, edge transformation, vertex transformation (Figure 1). Each of the three forms of the transformations may go through a rotation of $360^{\circ}$ in which the tessellation forms cycles from a closed state to an open state.

The present paper presents a method to determine the shapes of cover plates for planar radially retractable single DOF structures based on tessellation with regular polygons such that there are no overlaps in any configuration and no gaps in the closed configuration. A feasible design area, defined by the tessellation, can be covered with retractable polygonal plates and thus the designer is not required to use numerical analy-

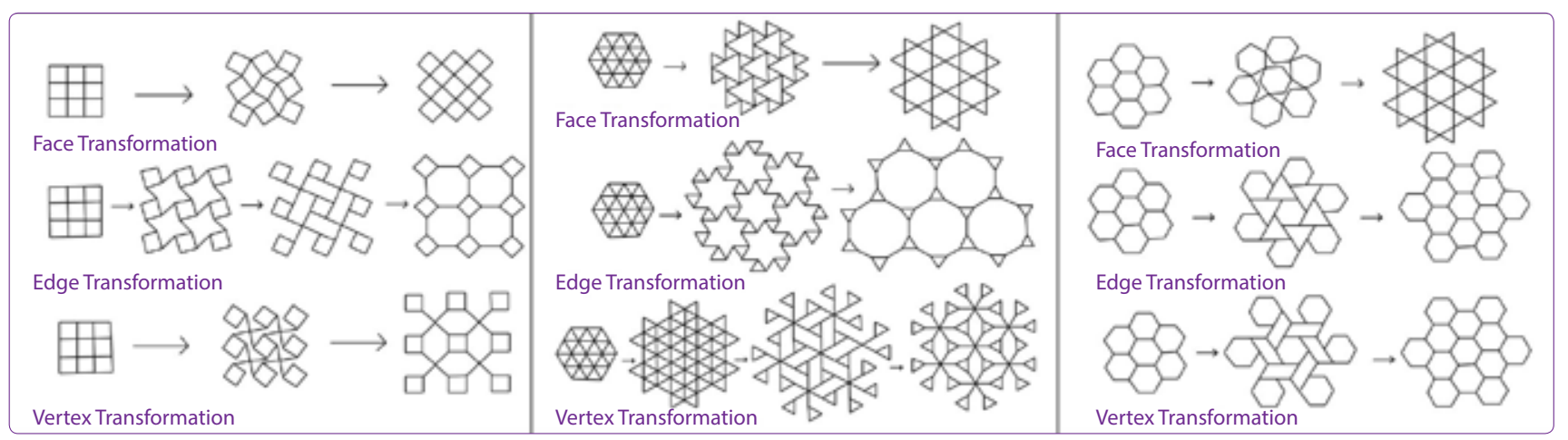

Figure 1. Two-dimensional Tessellation Transformations (Clinton, 1971). 
sis for shape optimization. Besides, this paper investigates the mobility analysis. It is required to prove that RRPS is single DOF.

\section{Tessellations}

Tessellation is a kind of mathematical technique which is used in science, art and architecture. Basically, tessellation or tiling means to cover a plane with distinct shapes without any gaps or overlaps by considering some methods. The origin of the tessellation comes from the Latin word tessella that was the square stone or tile used in ancient Roman mosaic. The word of tiling and mosaics are commonly synonyms for tessellation.

In mathematical approach, one of the first remarkable studies of tessellation was conducted by Johannes Kepler. In 1619, Kepler pictured the polygonal tessellation in his book. He wrote about the regular and semi-regular tessellations that are covering of a plane with regular polygons. ${ }^{[17]}$ In 1785, The Rev. Mr. Jones solved the problem of tiling of a plane around a point with regular polygons. ${ }^{[18]}$ Another important study was done by the Russian crystallographer E.S.Fedorov in 1891. He proved that every 1- uniform tessellation of the plane is constructed in accordance to one of the seventeen different groups of isometries. ${ }^{[19]}$ In the past there have been many attempts to try to describe and systematize the notation of tessellations. ${ }^{[20-28]}$ Grünbaum and Shephard brought together older results with new materials in their book. ${ }^{[29]}$

\section{Tessellations With Regular Polygons}

A tile is a simply connected topological disk in the Euclidean plane (Fig. 2). To remove the confusion between polygon and tile, Grünbaum and Shepherd de-

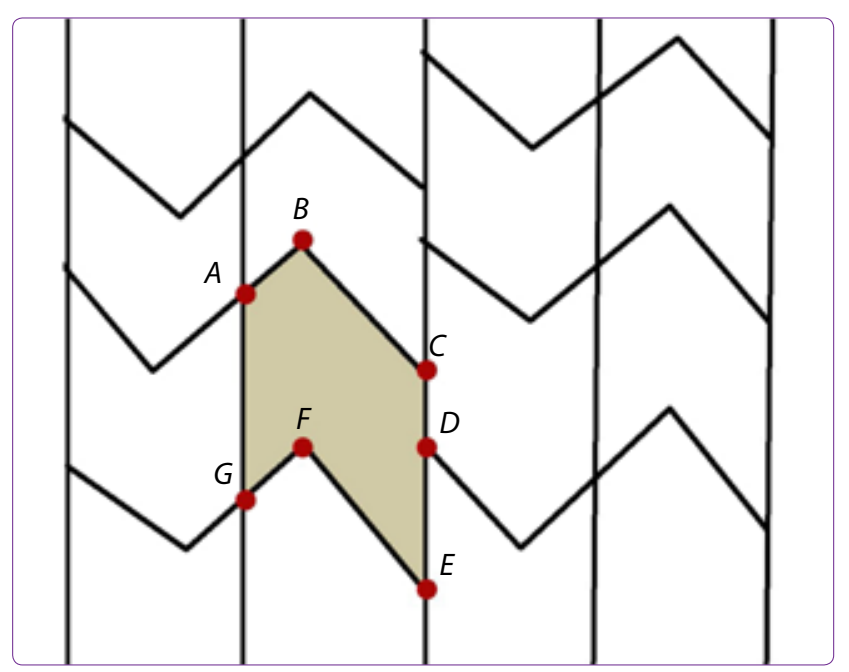

Figure 2. Illustration of a polygonal tiling. scribed the polygons with corners and sides while the tile is represented with vertices and edges. ${ }^{[29]}$

Fig. 2 is an illustration of basic element of tessellation. In this figure $A, B, C, D, E, F, G$ are corners but $A$, $C, D, E, G$ are vertices of the tessellation, $A B, B C, C E$, $E F, F G$ and $G A$ are sides while $A C, C D, D E, E G$ and $G A$ are edge.

A polygon is regular polygon if all angles are equal and all sides have same length. Tessellation with regular polygons is usually represented by the number of sides of the polygons around any vertex in the clockwise or anti-clockwise order. For instance, $\left(3^{6}\right)$ represents a regular tessellation in which each of the vertices are surrounded by six triangles, 3 is the number of the sides of a triangle and superscript 6 is the number of triangles around the referred vertex (Fig. 3 ).

The Rev. Mr. Jones developed a formula to solve the problem of tiling of a plane around a vertex with regular polygons. ${ }^{[18]}$ The formula is obtained by the help of interior angle of regular polygons and its combinations. The interior angle at each corner of a regular $\mathrm{n}$-gon $\{n\}$ is $(n-2) \pi / n$ radians (or $180(n-2) / n$ degrees) so that if an $n_{1}$ - gon $\left\{n_{1}\right\}$, an $n_{2}$-gon $\left\{n_{2}\right\}, \ldots$, an $n_{r}$-gon $\left\{n_{r}\right\}$, meet at a vertex of a tiling then

$$
\frac{n_{1-2}}{n_{1}}+\frac{\cdots \cdots}{\cdots \cdots}+\frac{n_{r-2}}{n_{1}}=2
$$

According to this formulation, 17 different arrangements of regular polygons fit around a vertex. Four of the arrangements have two distinct ways so; there are 21 ways to fit the regular polygons around a vertex (Fig. 4). ${ }^{[30]}$ However, not all of these can tessellate the plane. In these arrangements just eleven of them can

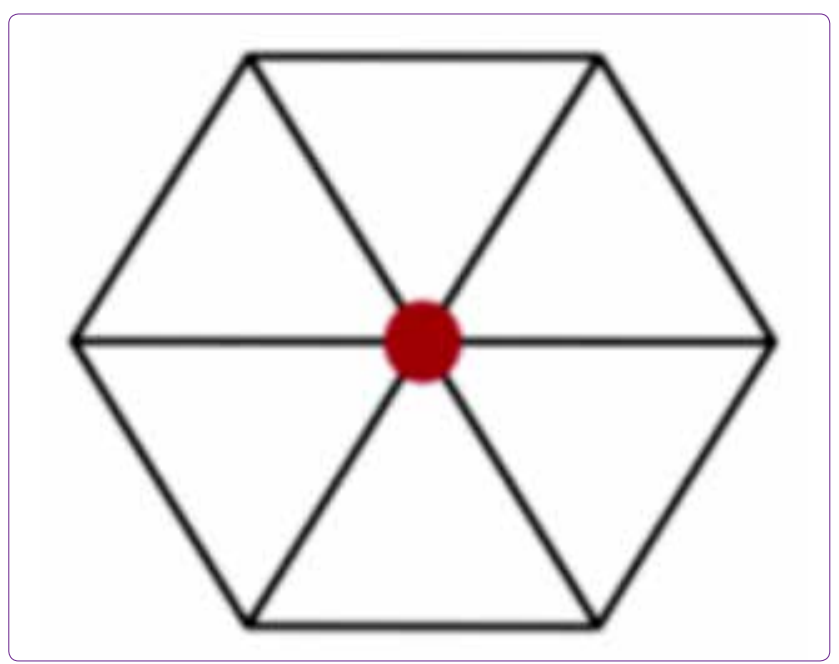

Figure 3. $\left(3^{6}\right)$ Triangle regular polygons fit around a vertex. 


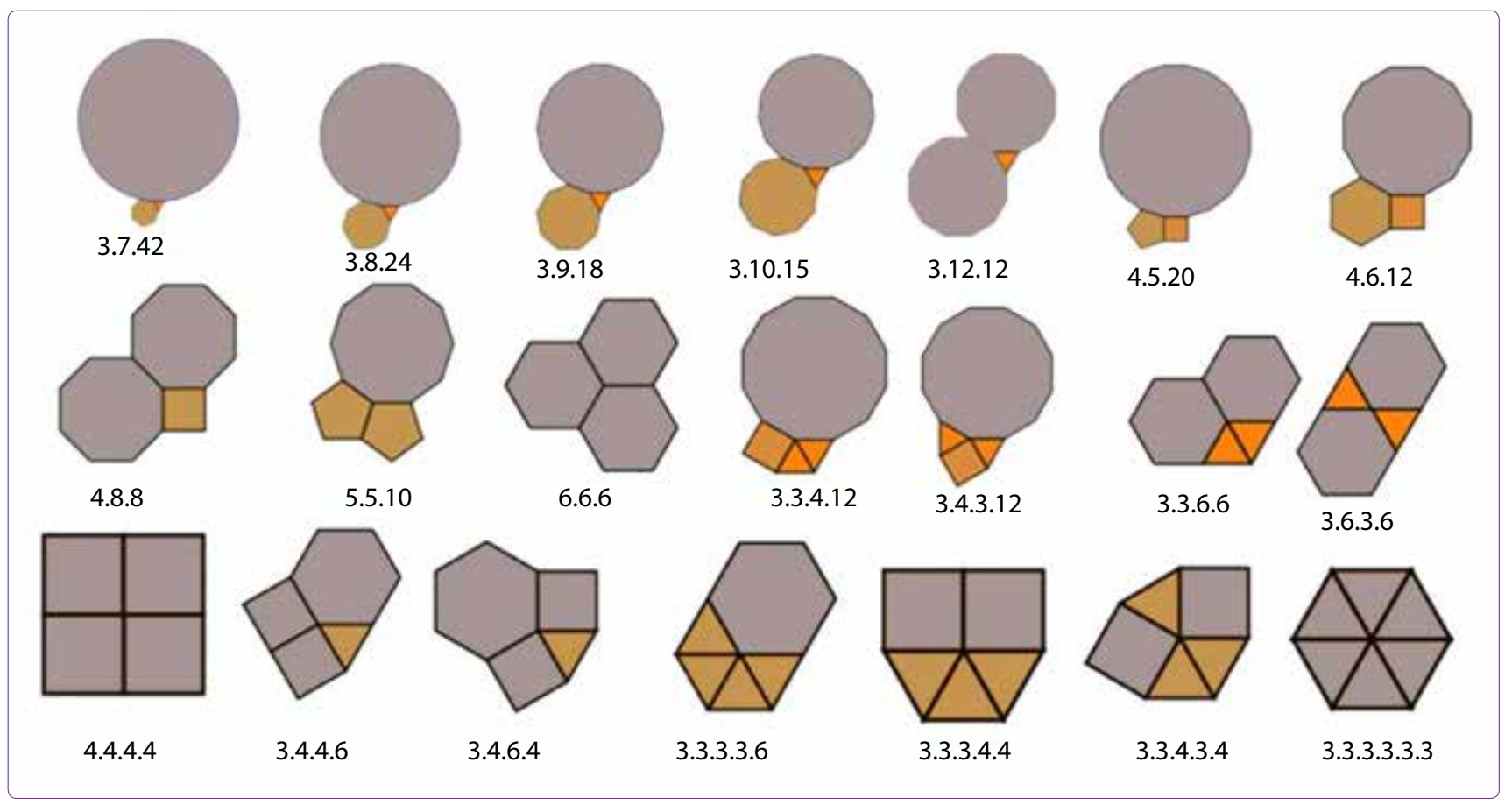

Figure 4. 21 arrangements of regular polygon combinations that fit around a vertex on plane.

cover the plane without any gaps or overlaps. These are three regular and eight semi-regular tessellations.

Many classifications of tessellations have been established in the literature. In this study, Johannes Kepler's classification based on the regular polygon shape is explored.

\section{K-Uniform Tessellations}

An edge-to-edge tiling by regular polygons is called $k$-uniform if its vertices form precisely $k$ transitivity classes with respect to the group of symmetries of the tiling. In other words, the tiling is k-uniform if and only if it is k-isogonal and its tiles are regular polygons. 1Uniform tessellations consist of the same arrangement of polygons and angles at each vertex. There are precisely eleven distinct edge-to-edge 1-uniform tessellations. In this group of 1-uniform tessellations, three of them are regular while eight of them are semi-regular.

Regular tessellations consist of a fixed number of specific regular $n$-gon at every vertex (Fig. 5). Semi regular tessellations consist of more than one type of regular polygon at a vertex but each vertex has the same configuration (Fig. 6).

There exist twenty distinct types of 2-uniform edgeto-edge tiling by regular polygons as shown in Fig. 7, namely: $\left(3^{6} ; 3^{4} .6\right)_{1^{\prime}},\left(3^{6} ; 3^{4} .6\right)_{2^{\prime}}\left(3^{6} ; 3^{3} .4^{2}\right)_{1},\left(3^{6} ; 3^{3} .4^{2}\right)_{2^{\prime}}$ $\left(3^{6} ; 3^{2} .4 .3 .4\right),\left(3^{6} ; 3^{2} .4 .12\right),\left(3^{6} ; 3^{2} .6^{2}\right),\left(3^{4} .6 ; 3^{2} .6^{2}\right),\left(3^{3} .4^{2} ;\right.$

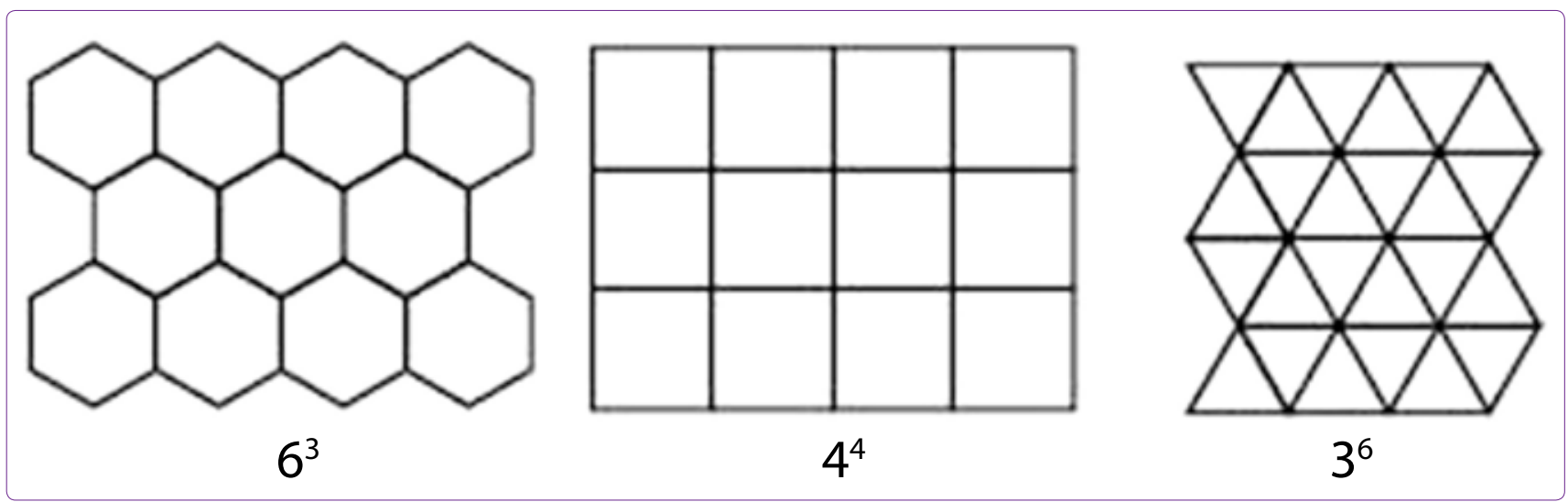

Figure 5. 1- Uniform Regular Tessellations 


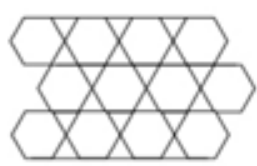

3.6.3.6

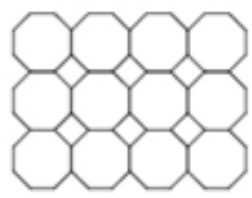

$4.8^{2}$

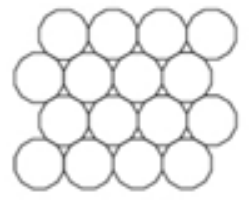

$3.12^{2}$.

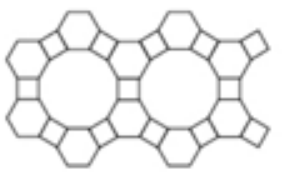

4.6.12

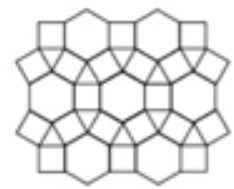

3.4.6.4

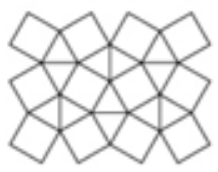

32.4.3.4.

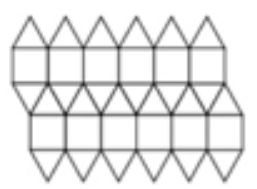

$3^{3} \cdot 4^{2}$

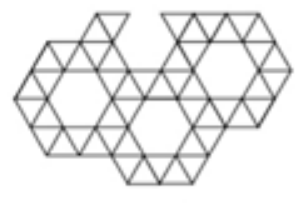

$3^{4} \cdot 6$ $\left.3^{2} \cdot 4.3 .4\right)_{1^{\prime}}\left(3^{3} \cdot 4^{2} ; 3^{2} \cdot 4 \cdot 3.4\right)_{2^{\prime}}\left(3^{3} \cdot 4^{2} ; 3.4 .6 .4\right),\left(3^{3} \cdot 4^{2} ; 4^{4}\right)_{1^{\prime}}$ $\left(3^{3} .4^{2} ; 4^{4}\right),\left(3^{2} .4 .3 .4 ; 3.4 .6 .4\right),\left(3^{2} .6^{2} ; 3.6 .3 .6\right),(3.4 .3 .12$; 3.12 $),\left(3.4^{2} .6 ; 3.4 .6 .4\right),\left(3.4^{2} .6 ; 3.6 .3 .6\right) 1^{\prime}, \quad\left(3.4^{2} .6\right.$; 3.6.3.6) $)_{2}$, and (3.4.6.4; 4.6.12).

Denote $K(k)$ as the number of distinct $k$-uniform tilings. $K(1)=11, K(2)=20, K(3)=39, K(4)=33, K(5)=$ $15, K(6)=10, K(7)=7$ and totally there are 135 distinct type of k-uniform tessellation. One of them is shown in Fig. 8.

\section{Duality of Tessellation}

To form the dual of a tessellation, firstly center of the each polygon is determined as a vertex then all centers are joined with each other. Any motion or change of scale affects the tessellation and it's dual. The triangle and hexagon tessellations are duals of each other, while the square tessellation is its own dual (Fig. 9).

\section{Method For RRPS Based On 1-Uniform Regular Tessellations}

Retractable regular tessellations consist of a number of interconnected polygons individually called plates in this paper. The physical connection between

Figure 6. 1- Uniform Semi-Regular Tessellations.

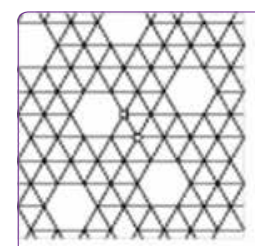

$\left(3^{6} ; 3^{4} .6\right)$

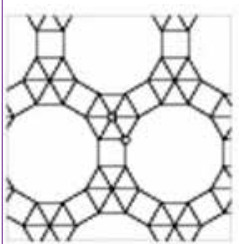

$\left(3^{6} ; 3^{2} .4 .12\right)$

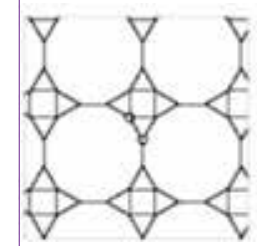

$\left(3.4 .3 .12 ; 3.12^{2}\right)$

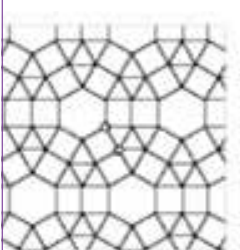

$\left(3^{3} .4^{2} ; 3.4 .6 .4\right)$

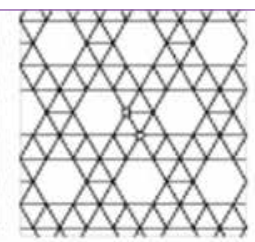

$\left(3^{6} ; 3^{4} .6\right)_{2}$

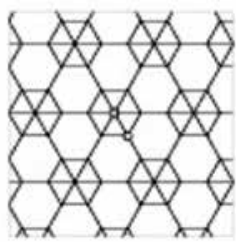

$\left(3^{6} ; 3^{2} \cdot 6^{2}\right)$

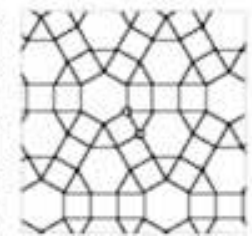

$\left(3.4^{2} .6 ; 3.4 .6 .4\right)$

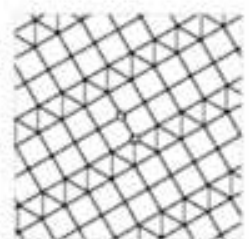

$\left(3^{3} \cdot 4^{2} ; 4^{4}\right)$

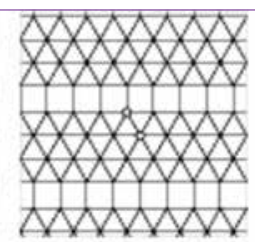

$\left(3^{6} ; 3^{3} \cdot 4^{2}\right)_{1}$

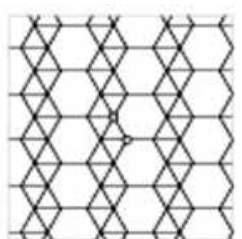

$\left(3^{4} .6 ; 3^{2} .6^{2}\right)$

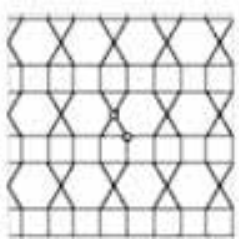

$\left(3.4^{2} .6 ; 3.6 .3 .6\right)$

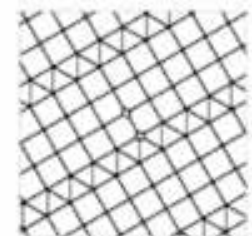

$\left(3^{3} \cdot 4^{2} ; 4^{4}\right)_{2}$

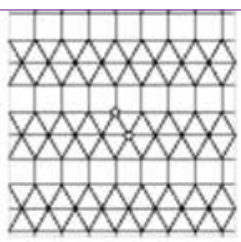

$\left(3^{6} ; 3^{3} \cdot 4^{2}\right)_{2}$

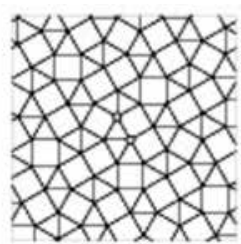

$\left(3^{3} .4^{2} ; 3^{2} \cdot 4.3 .4\right)$

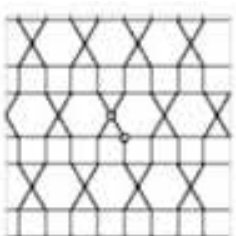

$\left(3.4^{2} .6 ; 3.6 .3 .6\right)$

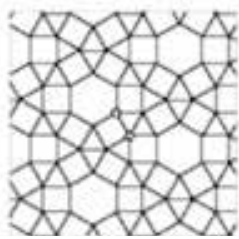

$\left(3^{2} .4 .3 .4 ; 3.4 .6 .4\right)$

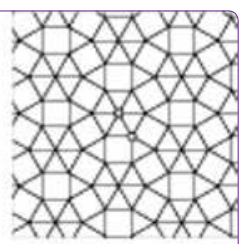

$\left(3^{6} ; 3^{2} \cdot 4.3 .4\right)$

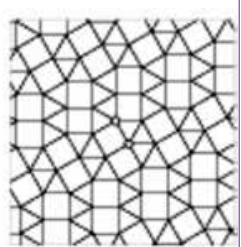

$\left(3^{3} .4^{2} ; 3^{2} .4 .3 .4\right)$

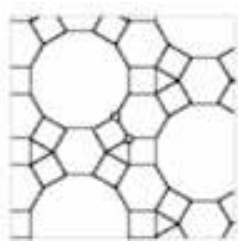

$(3.4 .6 .4 ; 4.6 .12)$

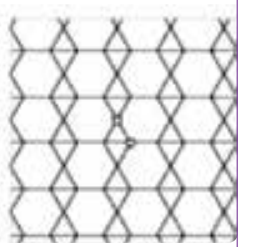

$\left(3^{2} .6^{2} ; 3.6 .3 .6\right)$
Figure 7. Twenty 2-Uniform Tessellations. 


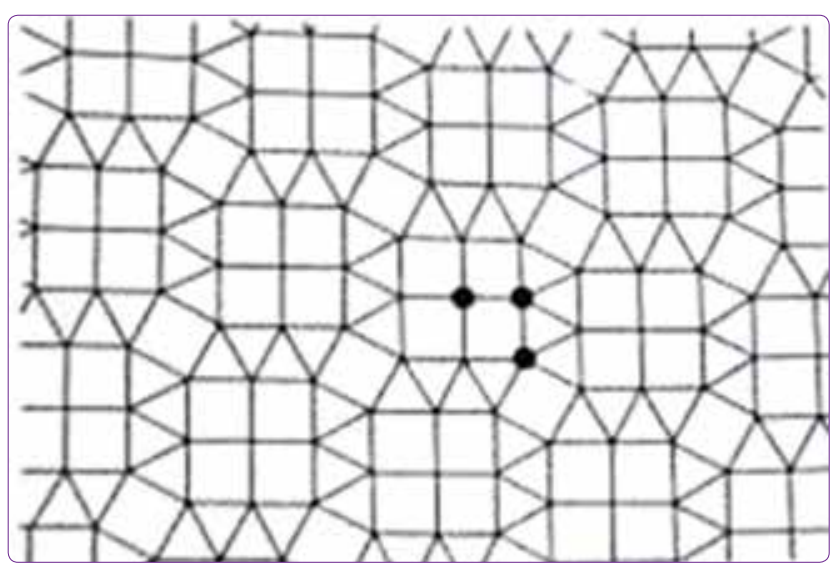

Figure 8. One of thirty nine 3 -Uniform Tessellations $\left(4^{4} ; 3^{3} .4^{2}\right.$; 4.3.4.32).

these plates are lower pairs (joints). The lower pairs are revolute joint and prismatic joint. Here the attention is on the plates connected with only revolute joints. Firstly the method identifies extra plate type and secondly the way of connecting plates to reach a RRPS. The following steps should be followed.

\section{RRPS Based On Hexagon Tessellation}

Step 1- By selecting the hexagon tessellation $\left(6^{3}\right)$ as demonstrated in Fig. 5, the flat plate type is determined. It is a plate with six nodes that are joints for the attachment with other plates as shown Fig. 10.

Step 2- The second step is determining the type of extra plate and its dimensions. The dual of the hexagon tessellation is triangle tessellation. Number of the sides of the triangle polygon gives us the type of extra plate. It is a plate with three nodes. Since all the polygons are hexagon, all the extra plates are same type. The size of the extra plate is determined from the hexagon polygons' size. First a hexagon tessellation is drawn, then the dimensions of the extra plate are

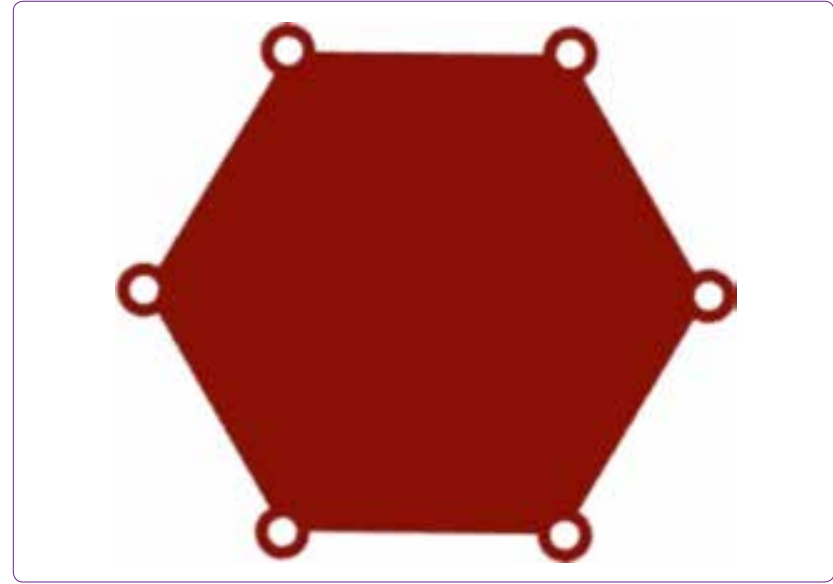

Figure 10. Hexagonal plate with six nodes.

determined by pointing one vertex to the three neighboring vertices as shown in Fig. 11. Since all edges are equal in hexagon regular tessellation, the distance between the three nodes on the extra plate are equal.

Step 3- Third step is assembling processes of the hexagonal plate and extra plates. In this step, blue colored hexagon tessellation and its red colored dual are drawn as shown in Fig. 12. Center points of the six hexagonal plates are placed on the intersection points of the hexagon tessellation and the dual. One more hexagon plate is placed on the center point of the hexagon. Then the six extra plates are placed on the vertices of the blue hexagon. Six more extra plates are placed in between the hexagon plates.

This method can be applied to the other regular tessellations $\left(3^{6}\right)$ and $\left(4^{4}\right)$. The triangle and hexagon tessellations are dual of each other. The construction of RRPS based on triangle tessellation is the same with the hexagon one. In this case, extra plate is a hexagon.

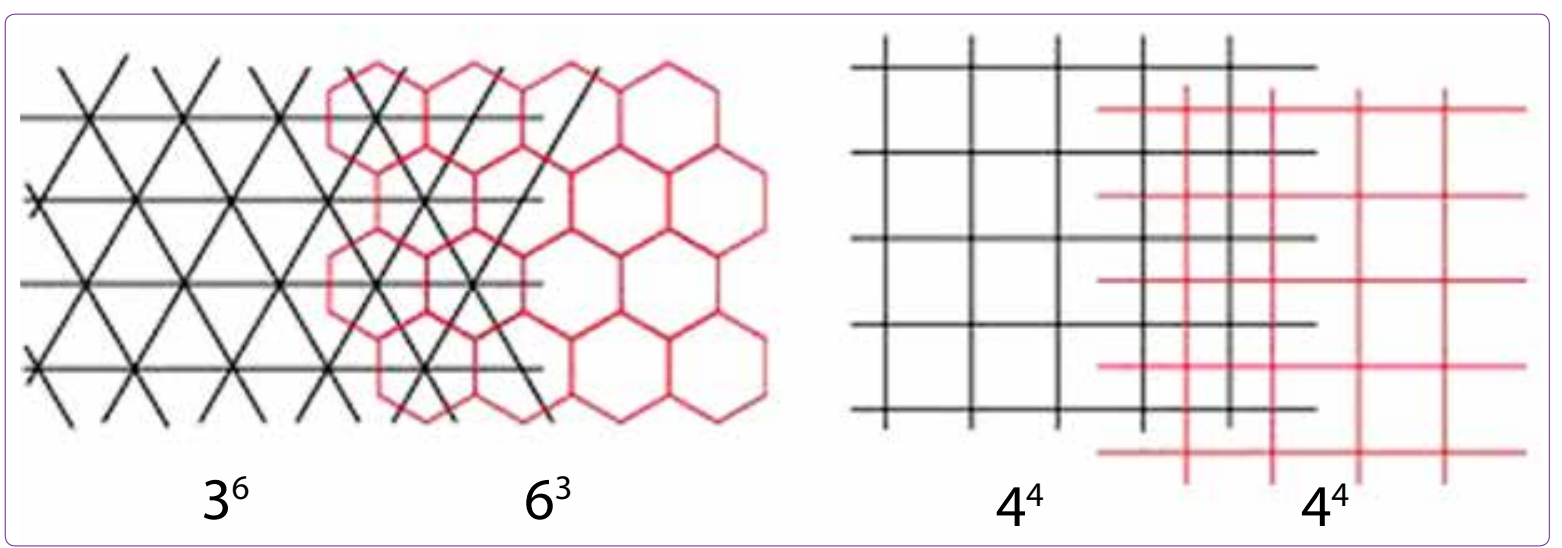

Figure 9. Dual of 1- Uniform regular tessellations. 


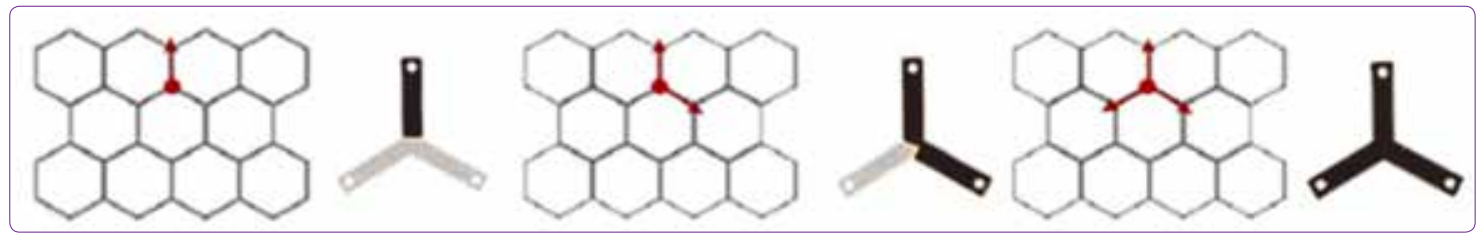

Figure 11. Process of obtaining the extra plate.

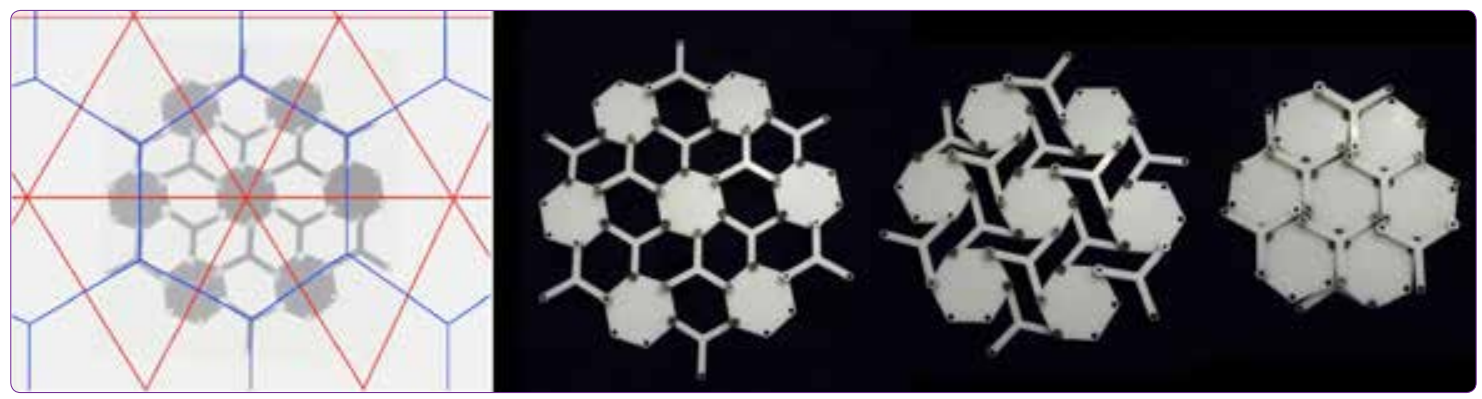

Figure 12. Assembling processes of the hexagonal plates and the retraction.

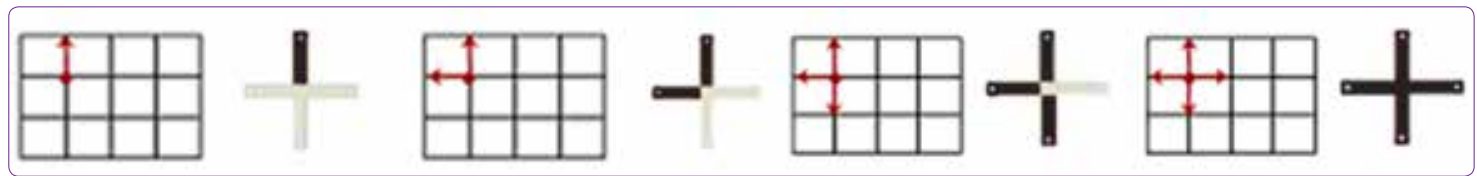

Figure 13. Process of obtaining the form of the extra plate.

\section{RRPS Based On Square Tessellation}

It is possible to construct the RRPS based on the square tessellation with the same method.

Step 1- By selecting the square tessellation $\left(4^{4}\right)$,

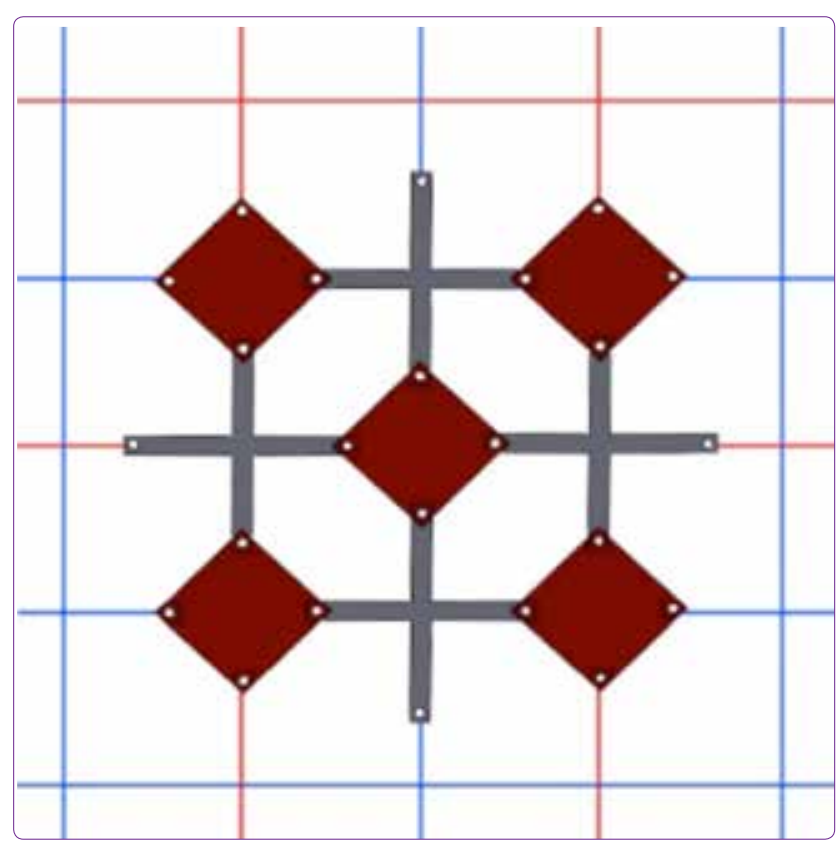

Figure 14. Assembling process of the square plates and the retraction. type of the flat plate is determined (Fig. 5). It is a plate with four nodes.

Step 2- As we mentioned above, the second step is finding the type of extra plate and its dimensions. The dual of the square tessellation is again square tessellation. Number of the sides of the square polygon gives us the type of the extra plate. It is a plate with four nodes. The size and form of the extra plate is determined by pointing one vertex to the four neighboring vertices as shown in Fig. 13.

Step 3- Third step is assembling processes of the square plates and extra plates. To determine the placement, blue colored square tessellation and its red colored dual are drawn as shown in Fig. 14. Four square form plates are placed on the points where the blue square tessellation and its red dual intersect. One more plate is placed on the center point of blue tessellation. Then extra plates are placed in between the square form plates. Fig. 15 shows the expanded and contracted forms of the RRPS.

\section{Mobility and Number of Excessive Plate Calculation}

In mechanism science mobility or degrees of freedom is one of the first fundamental concerns of both 

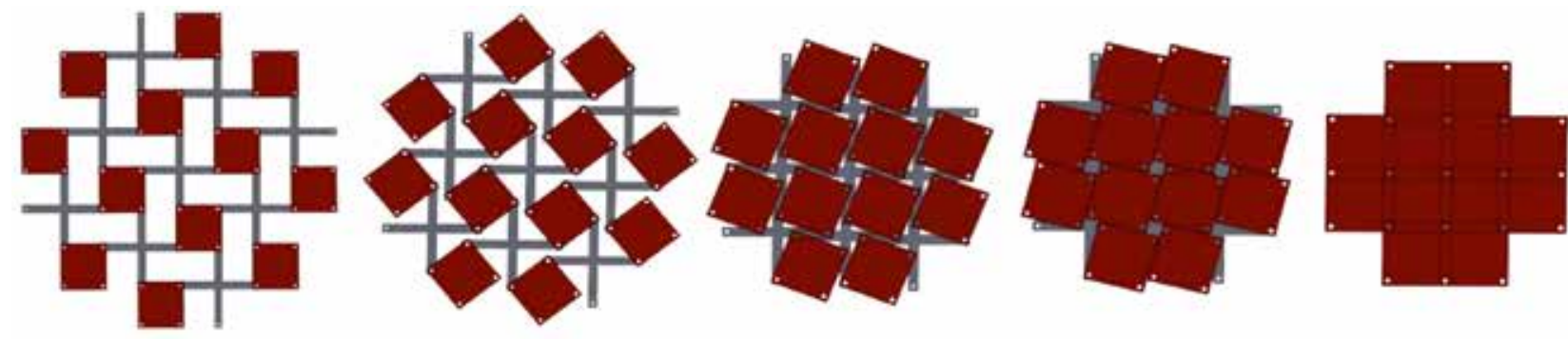

Figure 15. Expanded and contracted forms of the RRPS based on square tessellation.

design and analysis of the mechanisms. First the simplest module of the RRPS based on square tessellation is considered (Fig. 16). According to Grübler-Kutzbach formula; ;32]

$$
M=3(n-1)-2 j_{1}-2 j_{2}
$$

where; $M=$ degree of freedom or mobility

$\mathrm{n}=$ number of links

$\mathrm{j}_{1}=$ number of 1 DOF joints

$\mathrm{j}_{2}=$ number of 2 DOF joints

There are 9 links/plates and 12 single DOF joints. The mobility is calculated as $M=3(9-1)-2.12$ and found 0 . According to the equation the structure must be static not retractable. However after many simulations and models with number of plates and revolute joints, it is realized that the mobility of the retractable structure is always one. There are mechanisms with full-range mobility even though they do not meet the mobility cri-

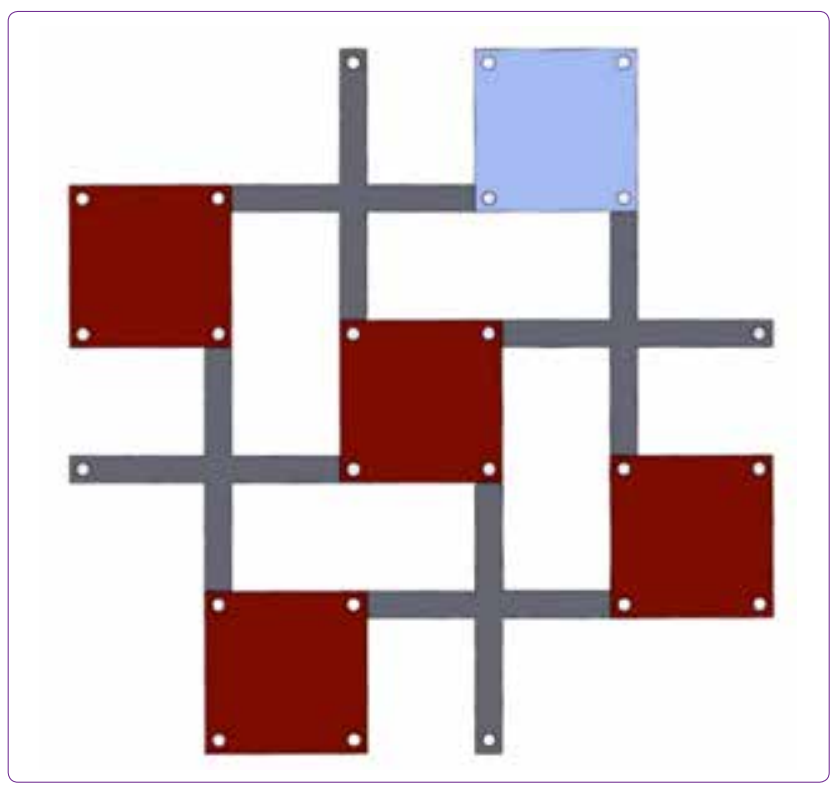

Figure 16. Simplest module of the RRPS based on square tessellation with one excessive plate terion. These mechanisms are called overconstrained. Their mobility is due to the existence of special geometry conditions among the links/plates and joint axes that are called overconstrained conditions. The simplest module is an overconstrained multi-loop mechanism due to the four parallelogram loops around the fixed link/plate. Grübler-Kutzbach formula do not fit for multi-loop overconstrained mechanisms.

In this paper, the mobility of the RRPS has been calculated according to Alizade and Freudenstein formula which is considered with the relation of joints and loops of the retractable structure. ${ }^{[31]}$

$$
\mathrm{M}=\sum_{i=1}^{j} f_{i}-\sum_{k=1}^{L} \lambda k+\mathrm{q}
$$

where, $\mathrm{j}$ is the total number joints, $f i$ is the total degrees of freedom of the $i^{\text {th }}$ joint, $L$ is the total number of independent loops, $q$ is the number of excessive plates (blue colored). Since there are only 1 DoF joints and the subspace of the mechanism is three, the equation becomes;

$$
M=J-3 L+q
$$

Where $\mathrm{J}$ is the total number of 1-DoF joints.

It is known that the mobility of the simplest retractable module is 1 . There are totally 4 loops and 12 revolute joints. According to the equation (4) variables $L=4$, $\mathrm{J}=12$ the mobility of the module is calculated as $\mathrm{M}=$ $12-3.4+q=1$, then the number of excessive plates $q=1$. Fig. 17 shows the contraction with and without excessive plate.

For the second case the simplest square retractable module is iterated as in Fig. 18. Two modules are sharing the fourth loop. There are totally 7 loops, 1 shared loop (4), 20 revolute joints. According to the equation (4) variables $L=7, J=20$ the mobility of the RRPS is calculated as $M=20-3.7+q=1$, then the number of excessive plates $q=2$. Fig. 19 shows the RRPS with and 


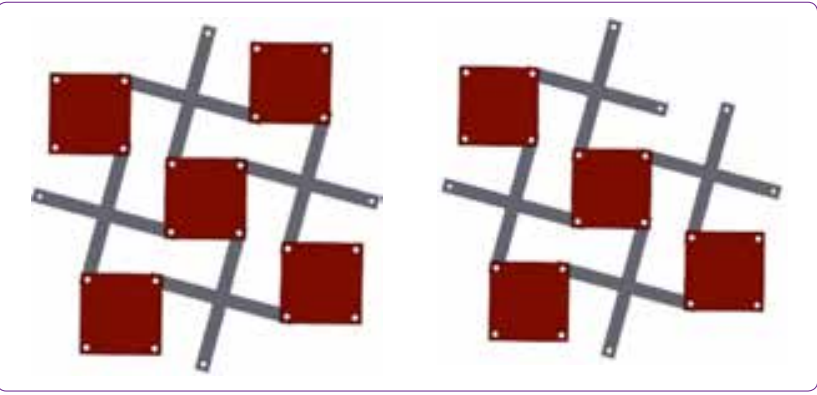

Figure 17. Simplest module of the RRPS based on square tessellation with and without excessive plate

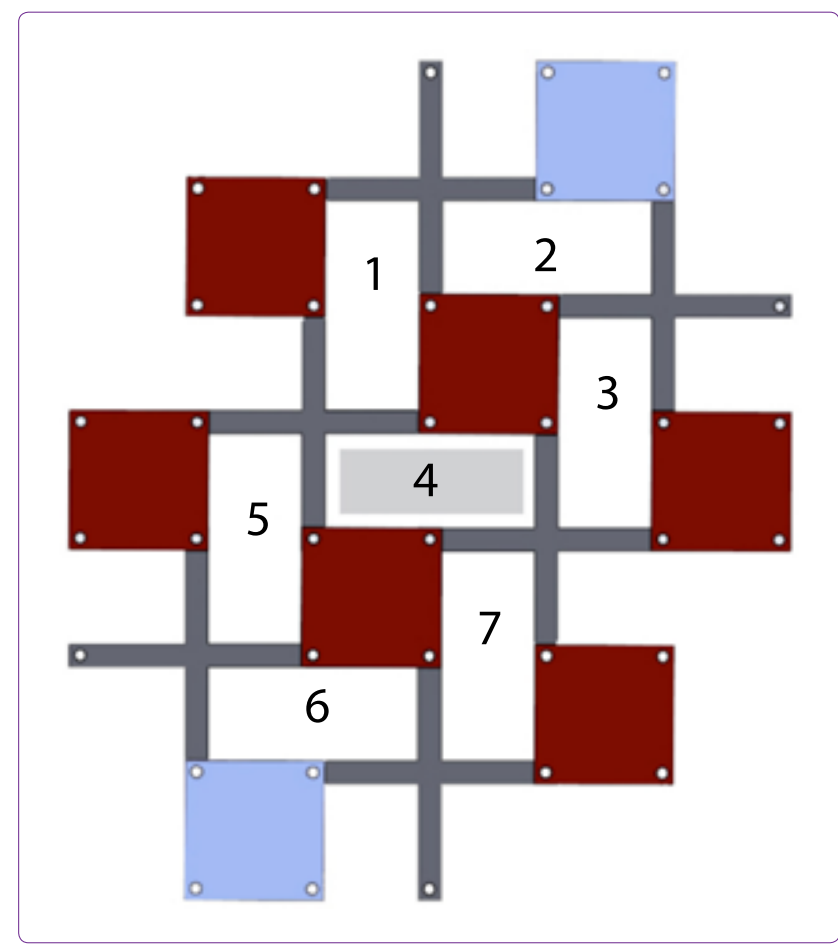

Figure 18. Iterated module with a shared loop and two excessive plates.

without two excessive plates. Excessive plates are displayed with blue color.

Note that each iteration of a new module that shares only one loop increase the excessive plate one more. If one more module is iterated as in Fig. 20, there are two shared loops ( 4 and 6$)$. There are totally 10 loops, 2 shared loops $(4,6), 28$ revolute joints. According to the equation (4) variables $L=10, J=28$ the mobility of the RRPS is calculated as $M=28-3.10+q=1$, then the number of excessive plates $q=3$. Fig. 21 shows the tessellation with and without three excessive plates.

After two identical iterations, with the third iteration the RRPS shares four loops (3-4-7-10) not three (Fig. 22). There are totally 12 loops, 4 shared loops, 32

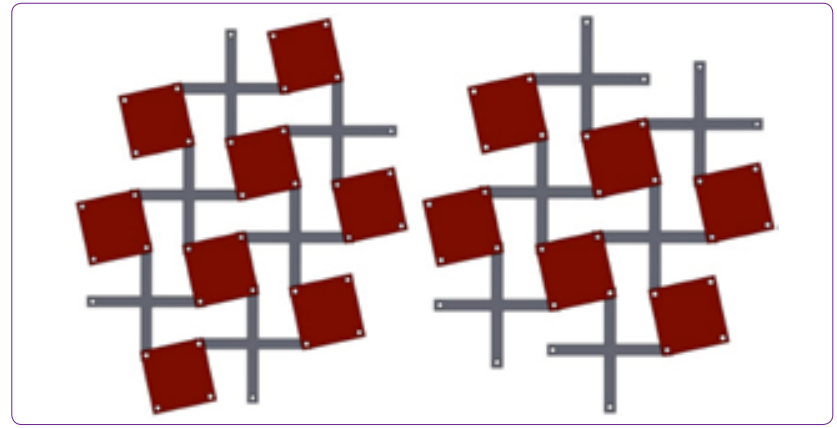

Figure 19. Iterated module with and without 2 excessive plates.

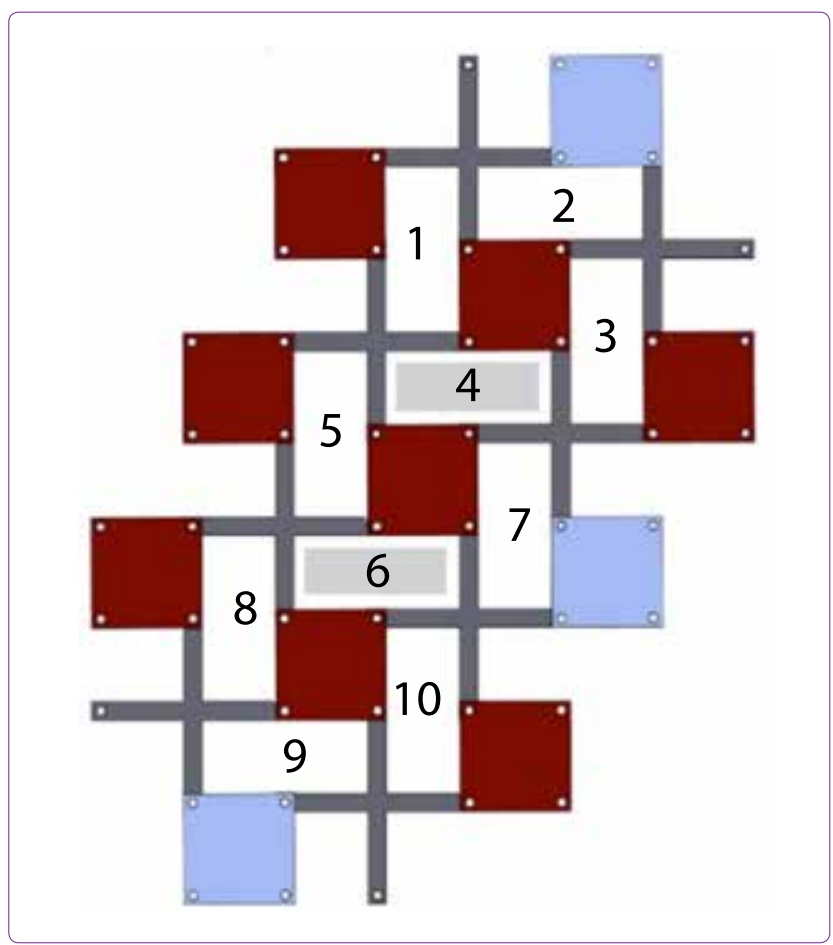

Figure 20. Two times iterated module with two shared loops and three excessive plates.

revolute joints. According to the equation (4) variables $\mathrm{L}=12, \mathrm{~J}=32$ the mobility of the structure is calculated as $M=32-3.12+q=1$, then the number of excessive plates $q=5$. Fig. 23 shows the RRPS with and without five excessive plates. After the last iteration, it should be noted that sharing two loops with one additional module adds two excessive plates to the tessellation instead of one. After these iterations it can be said that the number of excessive plates is equal to one plus the number of loops that are shared on the structure.

Same formula can be used to find the excessive plates in RRPS based on hexagon tessellation. Firstly the simplest module of the hexagon regular RRPS is considered. There are totally 12 loops, 30 revolute joints as shown in Fig. 24. According to the equation 


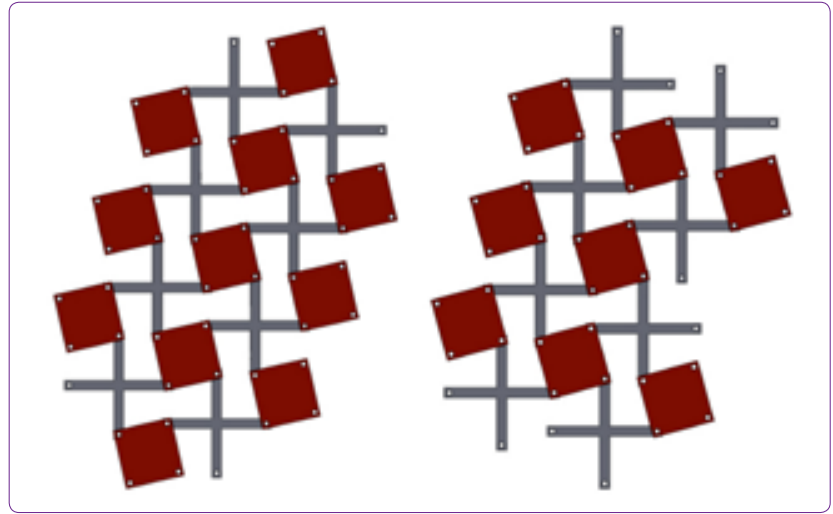

Figure 21. Two times iterated module with and without 3 excessive plates.

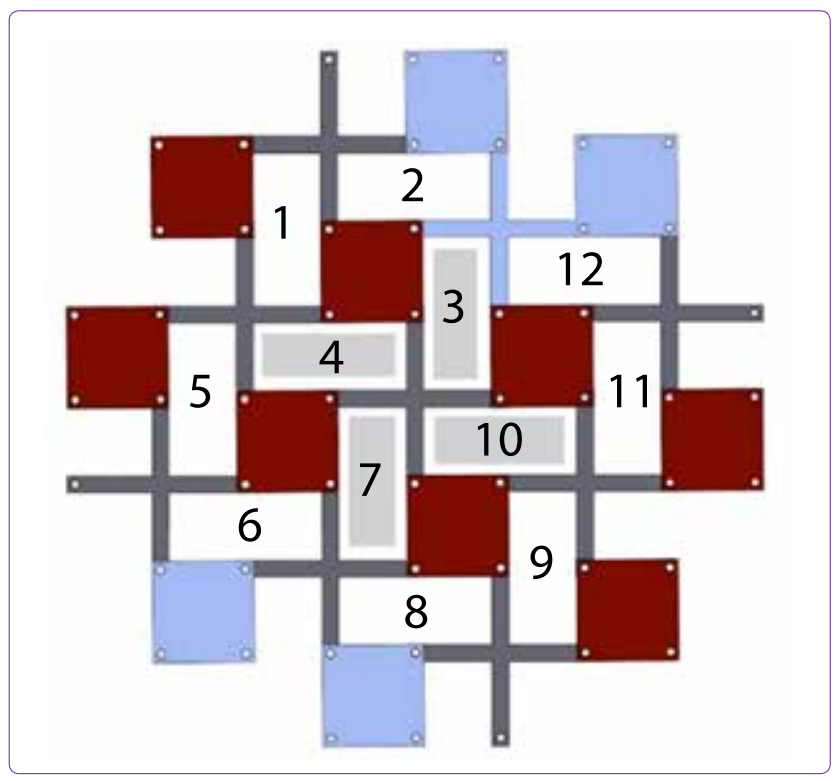

Figure 22. Three times iterated module with four loops and five excessive plates.

(4) variables $L=12, J=30$ the mobility of the RRPS is calculated as $M=30-3.12+q=1$. It is found that there are seven excessive plates which are displayed with blue color. Fig. 25 shows the RRPS without seven excessive plates.

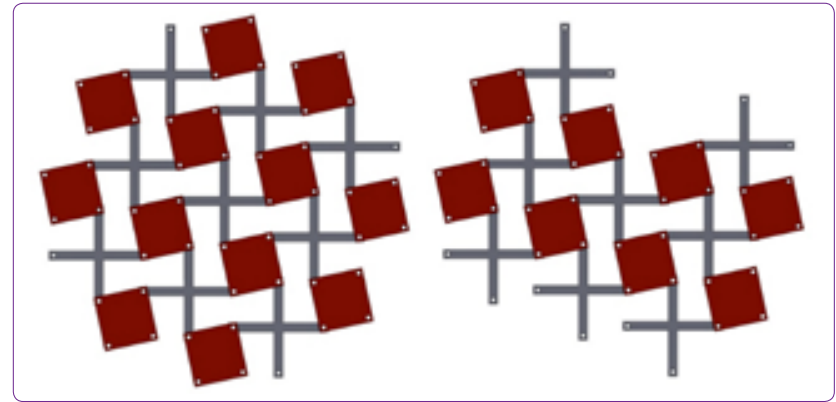

Figure 23. Three times iterated module with and without 5 excessive plates.

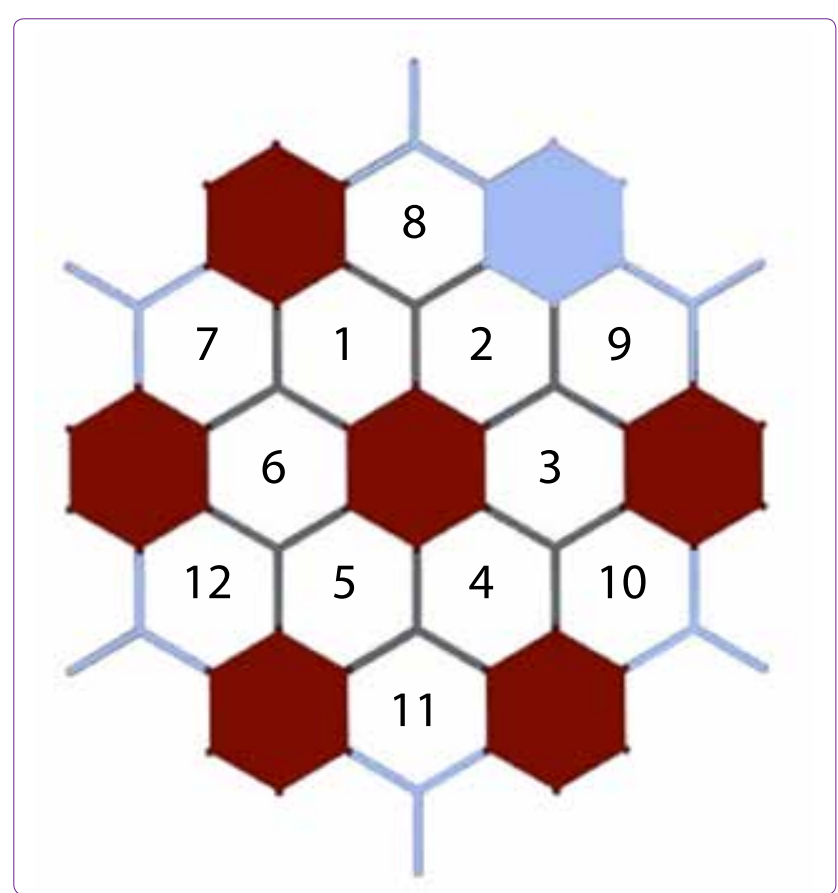

Figure 24. Simplest module of the RRPS based on hexagon tessellation.

For the second case the simplest module is iterated. There are totally 19 loops, 5 shared loops $(1,7,6,5$, 12), 46 revolute joints as in Fig. 26. According to the equation (4) variables $L=19, \mathrm{~J}=46$ the mobility of the RRPS is calculated as $M=46-3.19+q=1$. It is found

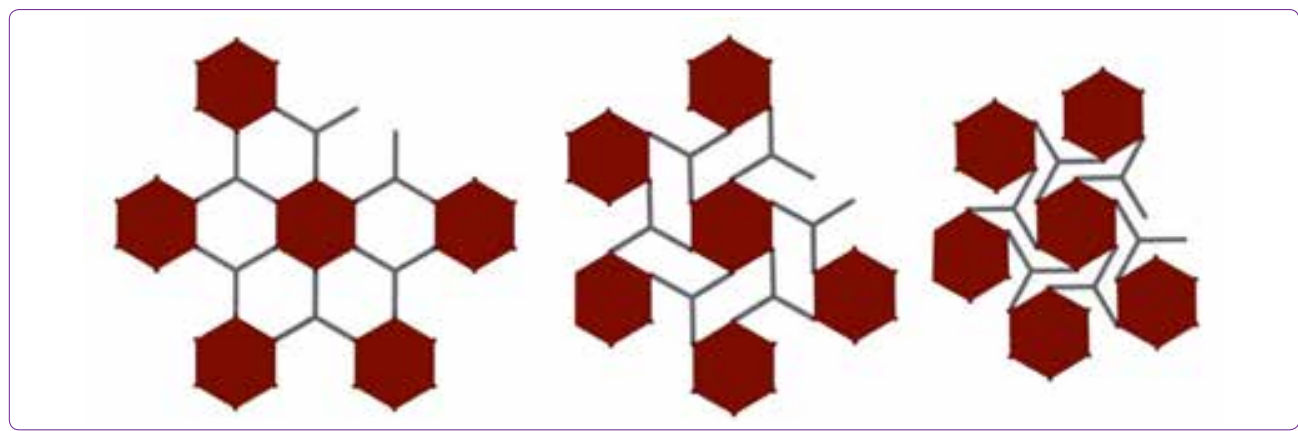

Figure 25. Contraction of the RRPS based on hexagon tessellation without seven excessive plates. 


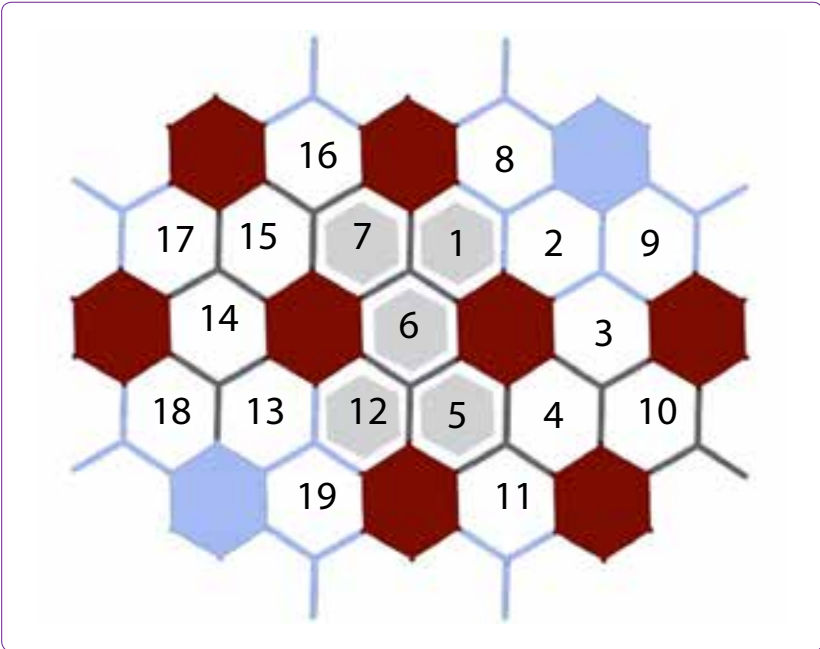

Figure 26. Iterated module with five shared loops and twelve excessive plates.

that there are twelve excessive plates. Fig. 27 shows the RRPS without twelve excessive plates.

When simplest module is two times iterated, there are twenty-six loop, 10 shared loops $(1,7,6,5,12,13$, $14,15,17,18), 62$ revolute joints on the structure as in Fig. 28. According to the equation (4) variables $L=26$,
$\mathrm{J}=62$ the mobility of the RRPS is calculated as $\mathrm{M}=62$ $3.26+q=1$. It is found that there are seventeen excessive plates which are displayed with blue color. Fig. 29 shows the RRPS without seventeen excessive plates.

Note that each iteration adds seven loops, sixteen joints, five sharing loops and five excessive plates to the whole RRPS. If the two iteration procedure is combined, a new theorem can be introduced to the literature related with the mobility calculations of the RRPS based on regular tessellations.

Theorem: Number of excessive links is equal to the number of excessive links of simplest module plus the number of loops that are shared during the whole iteration process.

\section{Retraction Capability of Scaled Modules}

The proposed retractable module can get endlessly small while still providing the same expansion and contraction. At the same time, modules of different sizes can be connected to each other without losing their retractable capability. To reach this aim, a module is scaled $1 / 2$ down and two number of this module connected with $1 / 1$ scale module in Fig. 30.

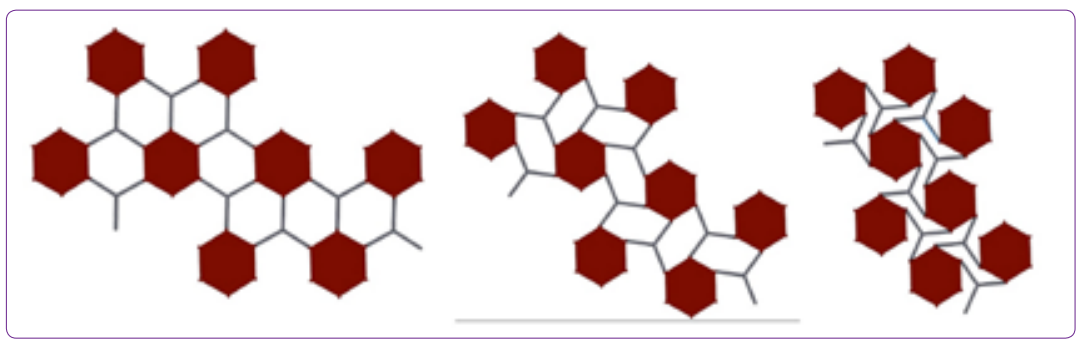

Figure 27. Iterated module without twelve excessive plates.

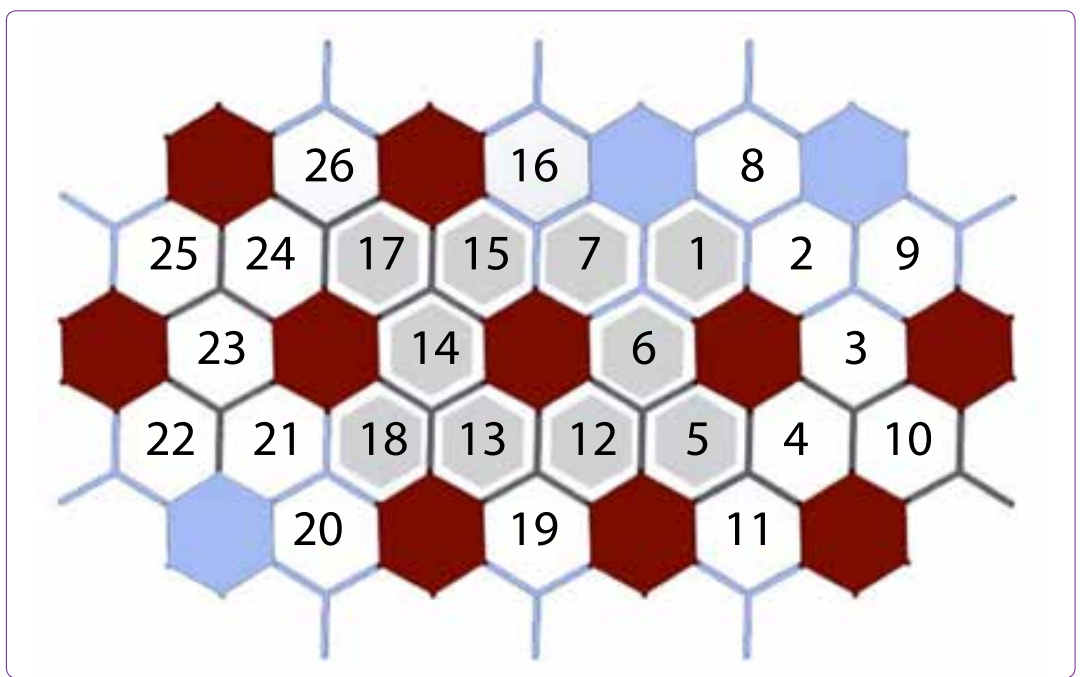

Figure 28. Two times iterated module. 


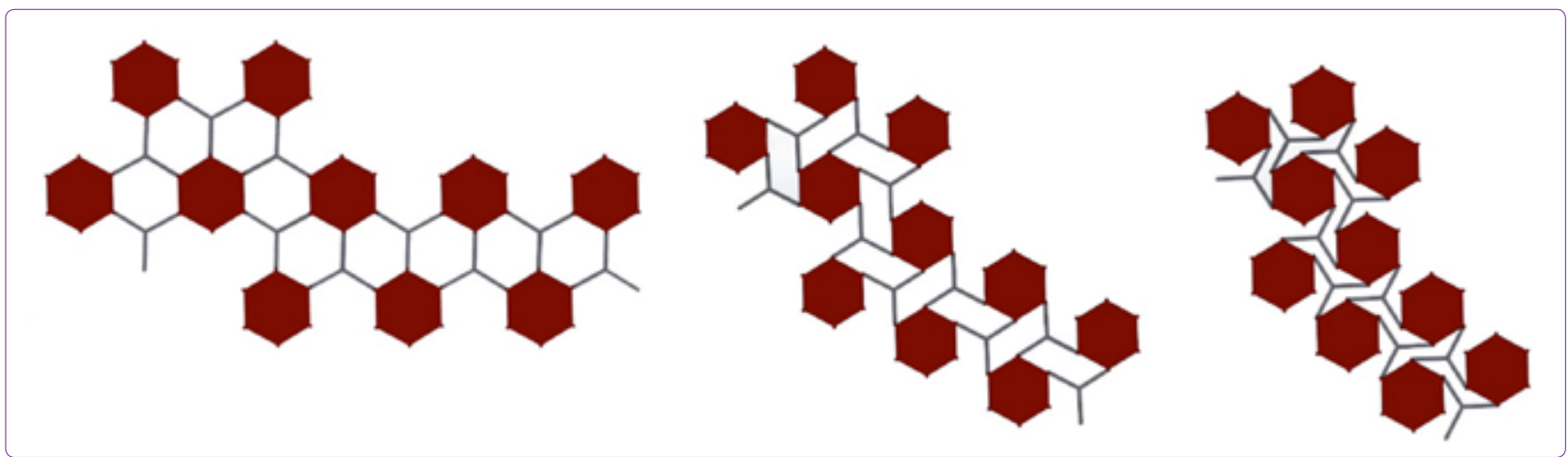

Figure 29. Two times iterated module without seventeen excessive plates.

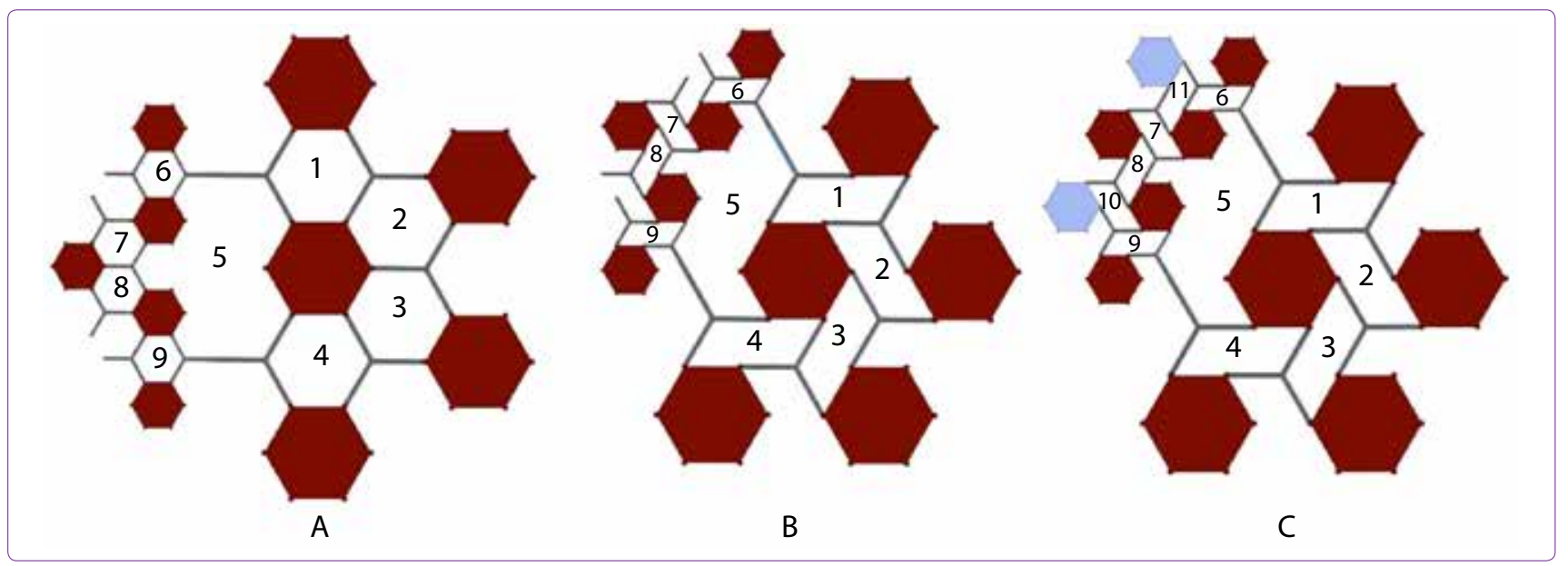

Figure 30. Contraction capability of the scaled modules.

Alizade and Freudenstein formula can be used again. Fig. 30a is the simplest scaled and connected modules. There are totally 9 loops, 28 revolute joints. According to the equation (4) variables $L=9, J=28$ the mobility of the RRPS is calculated as $M=28-3.9+q=1$. It is found that the mobility of the RRPS is equal to 1 without any

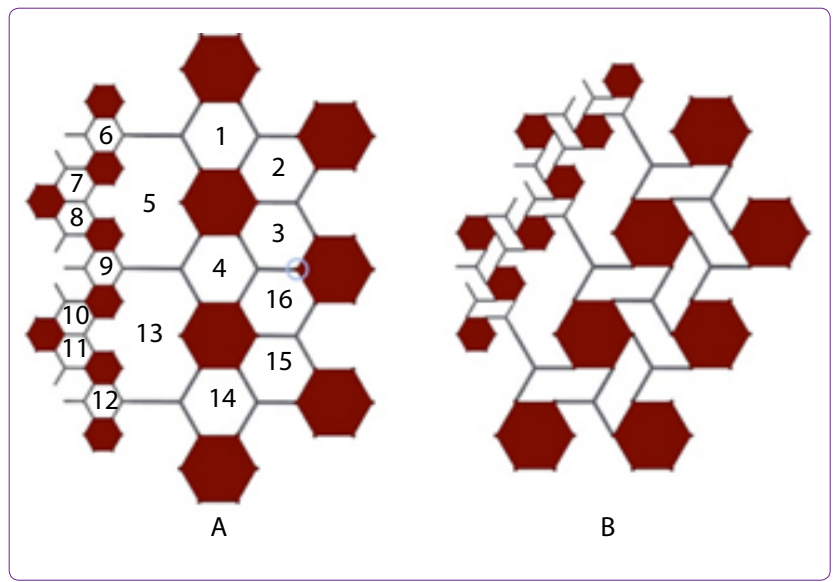

Figure 31. Contraction capability of the iterated scaled modules. excessive plate. Fig. 30b shows the contraction of the modules. Fig. 30c shows the same modules with two excessive plates. With these two excessive plates the new RRPS has 11 loops and 32 joints. According to the equation (4) variables $L=11, J=32$ the mobility of the RRPS is calculated as $M=32-3.11+q=1$. It is found

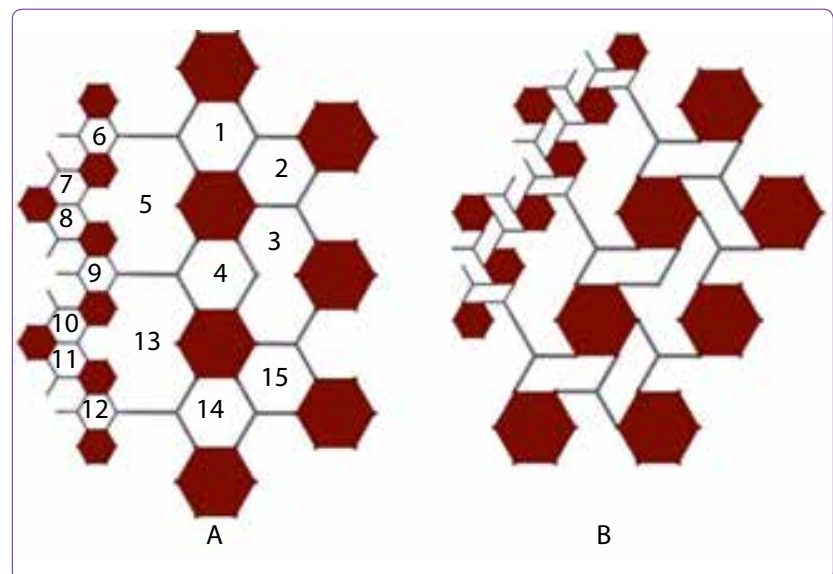

Figure 32. Contraction of the iterated scaled modules without passive joint. 


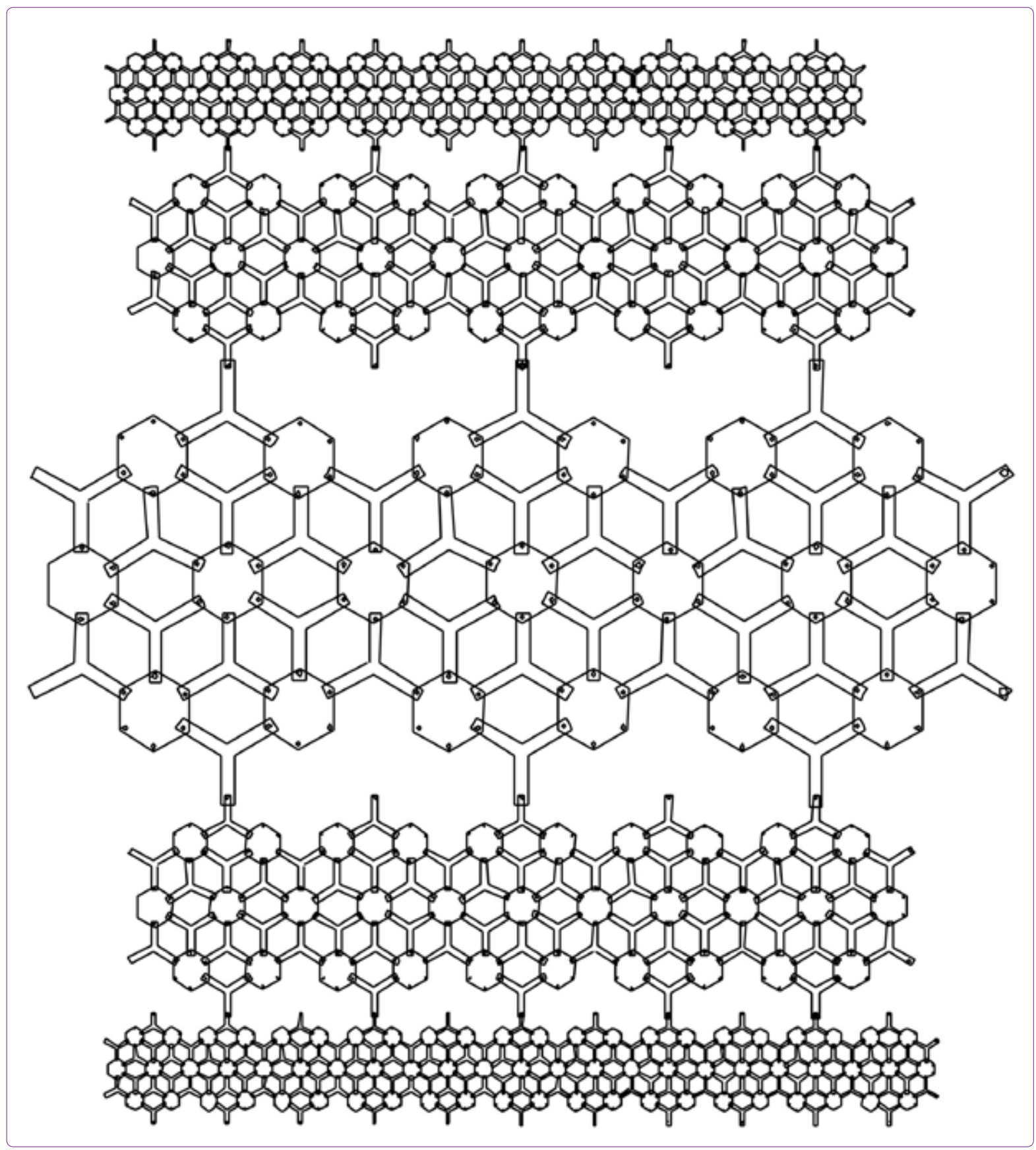

Figure 33. Scaled modules at different zones.

that the mobility of the RRPS is again equal to 1 with two excessive plates.

Fig. 31 shows the contraction capability of the iterated scaled modules without any excessive plates. There are totally 16 loops, 47 revolute joints. If the equation (4) variables $L=16, J=47$ are inserted to the formula $M=47-3.16=-1$. Even though RRPS does not meet mobility criterion it retracts because there is one passive joint as shown in Fig. 31a with a blue circle. Fig.
32 shows the contraction of the RRPS without passive joint and any excessive plate. Now there are totally 15 loops, 46 revolute joints. If the equation variables $\mathrm{L}=15, \mathrm{~J}=46$ are inserted to the formula $\mathrm{M}=46-3.15$ $=1$.

\section{Architectonic Applications}

In order to illustrate the architectonic potential of the RRPS, this paper shows illustrations of a project of exterior sun shade designed by the authors. At the 


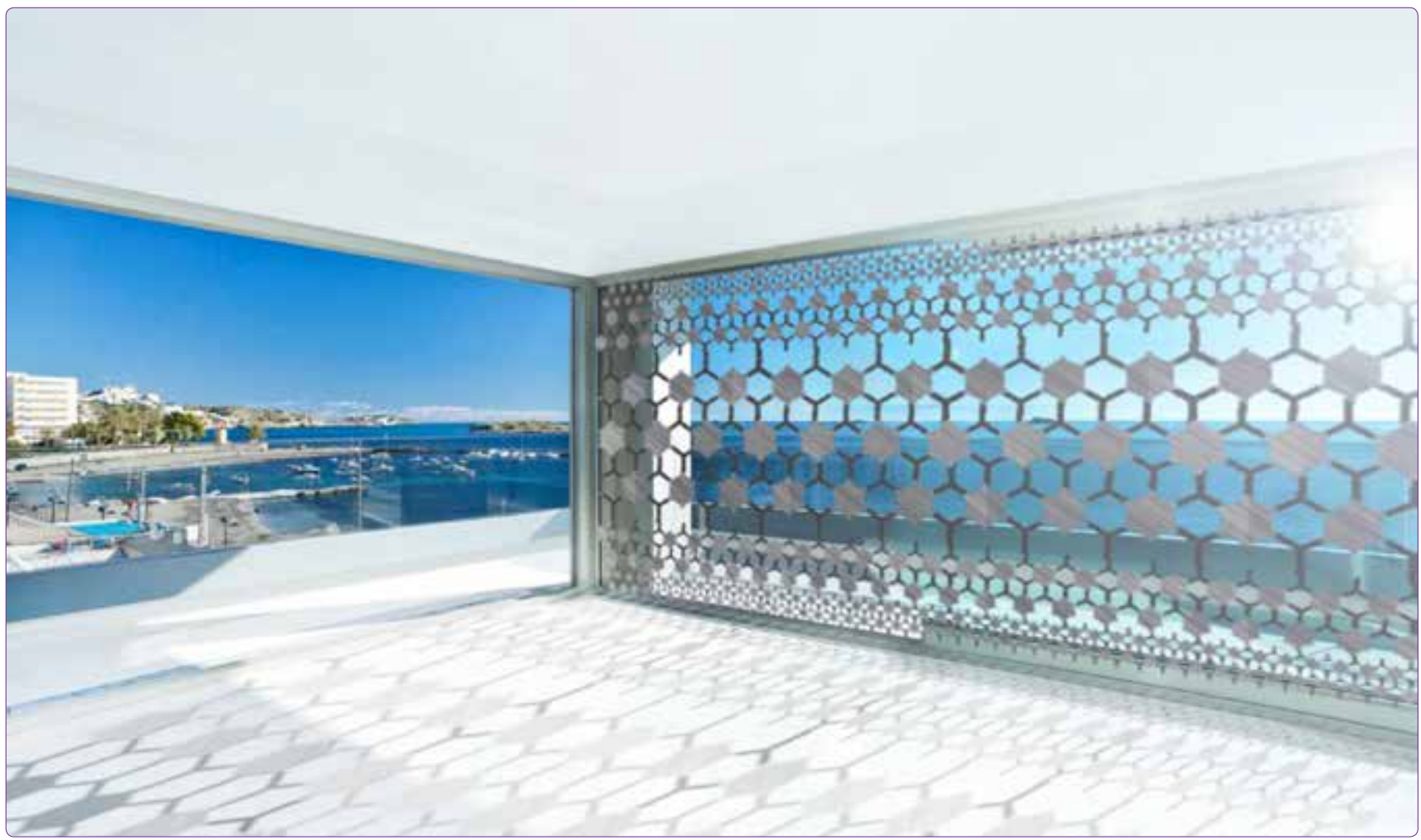

Figure 34. RRPS application as an exterior sun shade for a building facade.

present time buildings consume almost $50 \%$ of the energy today. With regard to overheating, transparent parts of the building envelope (facades and roof) have a large effect on the building's energy consumption. Architects can play a major role in the reduction of energy consumption. A RRPS based on hexagon tessellation is proposed to be an exterior sun shade for a building façade in order to limit cooling loads. The exterior sun shade consists out of an array of expandable modules varying in size to fulfill criteria like specific views, transparency and aesthetics. If a facade is divided into horizontal zones, the center zone is mostly used for a high degree of visual contact. Contrarily to the center zone, the upper and bottom zones should be protected from direct solar radiation. Therefore, a retractable module can be scaled and multiplied to have repetitive elements without losing the retraction capability in different zones. By changing the size of the module, the number of modules to provide the same retraction will have to be adjusted in the zones. If the module does not have to be big for visual contact, it can be scaled down for shading purpose at the upper and bottom zones. The openings in the center zone are aimed to be bigger than the openings on the top and at the bottom. According to the scenario, the center components of the retractable modules are maximized while the edge components get smaller in the upper and bottom zones (Fig. 33).

Figures 34 shows retractable shading mechanism providing visual contact in the center zone and protection at the upper and bottom zones.

\section{Conclusion}

In this paper, a method has been presented for the development of radially retractable plates structures based on 1-uniform regular tessellations. According to the method, various single degree of freedom RRPSs based on square and hexagon tessellations are developed. It is understood that extra plates are necessary in between the square or hexagon polygons to achieve the retraction. Mobility analysis is done with Alizade Freudenstein formula for every RRPS and it is explored that there are excessive plates. These excessive plates can be eliminated one by one without effecting the retraction. Finally, scaled plates have been connected and proved that RRPS still achieves the retraction. It is obvious that a better understanding and translating geometric knowledge of tessellation could be a foundation for developing a new source of concepts in mechanism science and kinetic architecture. With this idea, a RRPS based on hexagon regular tessellation is proposed to a building façade as a sun shade to reduce the energy consumption. 


\section{References}

1. Candela, F., Perez, P. E., Calatrava, S., Escrig, F. and Perez, V.J. (1993) "Arquitectura Transformable" Escuela Tecnica Superior De Arquitectura De Sevilla, Spain.

2. Escrig, F. and J.P. Valcarcel (1986) "Analysis of Expandable Space Bar Structures" Edited by K. Heki. Proceedings of IASS Symposium on Shells, Membranes, and Space Frames, Osaka, Japan: Elsevier Science Publishers, p:269-276

3. Escrig, F. (1996) "General Survey of Deployability in Architecture" Edited by F. Escrig and C.A. Brebbia. Proceedings of MARAS'96:2nd International Conference on Mobile and Rapidly Assembled Structures. Seville, Spain: Computational Mechanics Publications, p: 3-22.

4. Zeigler, T. (1997) U.S. Patent. 4.026.313.

5. Hernandez, C., Zalewski, W. (1993) "Expandable Structure For The Venezuelan Pavi1ion At Expo'92", Space Structures4, Edited by G.A.R. Parke and C.M. Howard, Thomas Telford, London, Vol.2, p: 1710-1719.

6. Gantes, C.J., J.J. Connor, Rosenfeld Y. and R.D. Logcher (1994) "A Systematic Design Methodology for Deployable Structures" International Journal of Space Structures, Vol. 9, no. 2, p: 67-86.

7. Hoberman, C. (1990) "Reversibly Expandable Doublycurved Truss Structure", US Patent, No. 4942700.

8. Hoberman, C. (1991) "Radial Expansion Retraction Truss Structure", US Patent, No. 5024031.

9. You, Z. and Pellegrino, S. (1997) "Foldable bar structures", International Journal of Solids and Structures, Vol. 34, No. 15, pp. 1825-1847.

10. Kassabian, P., You, Z. and Pellegrino, S. (1999) "Retractable roof structures", Proceedings of the Institution of Civil Engineers- Structures and Buildings, Vol. 134, No. 2, pp. 45-56.

11. Jensen, F. (2001) “Cover Elements for Retractable Roof Structures", PhD Dissertation, University of Cambridge, Cambridge, UK.

12.Jensen, F. and Pellegrino, S. (2002) "Expandable Structures formed by Hinged Plates" Fifth International Conference on Space Structures, University of Surrey.

13. Lou Y., Mao D., You Z. (2007) "On a type of radially retractable plate structures", International Journal of Solids and Structures 44, p: 3452-3467.

14. Buhl T., Jensen F., Pellegrino S. (2004) "Shape optimization of cover plates for retractable roof structures" Com- puters and Structures 82, p: 1227-1236.

15. Rodriguez C. and Chilton J. (2003) "Swivel Diaphragm" Journal of the International Association for Shell and Spatial Structures, Vol. 44, p: 181-188.

16. Chilton J. (1971) "Advanced Structural Geometry Studies", National Aeronautics and Space Administration, Washington D.C.

17. Kepler, J. (1619) “Harmonice Mundi" Lincii.

18. Seymour, D., Britton, J. (1989) "Introduction to Tessellations", Dale Seymour Publications, United States of America.

19. Chavey, D. Perry. (1984) "Periodic Tilings and Tilings by Regular Polygons" PhD Thesis, University of WisconsihMadison.

20. Bourgoin, J. (1873) "Theories de I' ornament" A.Levy, Paris.

21. Bourgoin, J. (1880) "Grammaire elementaire de l'ornement, pour server $\alpha$ la thèorie et $\alpha$ la pratique des arts et $\dot{\alpha}\lceil$ ¡ pratique des arts et $\dot{\alpha}\lceil$ enseigment" Delagrave, Paris.

22. Bourgoin, J. (1891) Etudes architectoniques et grahiques. Tome 2. Leçons de graphique èlèmentaire" Charles Schmid, Paris.

23. Day, L.F. (1903) "Patter Design" Batsford, London. New Edition. Taplinger, New York.

24. Dresser, C. (1862) "The Art of Decorative Design" Day and Son, London.

25. Edwards, E.B. (1932) “Dynamarhythmic Design” Century, New York.

26. Meyer, F.S. (1988) "Handbuch der Ornamentik" Leipzing.

27. Schauermann, F.L. (1892) "Theory and Analysis of Ornament Applied to the Work of Elementary and Technical Schools" Sampson Low, Marston, London.

28. Wersin, W. Von. (1953) "Das Elementare Ornament und seine Gesetzlichkeit" Maier, Ravensburg.

29. Grünbaum, B., Shephard, G. (1986) "Tilings and Patterns", W. H. Freeman and Company, New York.

30. Kinsey, L.C., Moore, T.E. (2002) "Symmetry, Shape and Space: An Introduction to Mathematics Through Geometry", Key College Publishing, New York.

31. Alizade R., Bayram C., Gezgin E. (2006) "Structural Synthesis of Serial Platform Manipulators", Mechanism and Machine Theory 42(5), p: 580-599.

32. Norton Robert L. (2004) "Design of Machinery" Mc Graw Hill. 